\section{Pollen Morphology, Viability, and Germination of Tanacetum vulgare $\mathrm{L}$.}

Nina Devrnja, Jelena Milojević, Ljiljana Tubić, Snežana Zdravković-Korać, Aleksandar Cingel, and Dušica Ćalić1 Institute for Biological Research "Siniša Stanković," University of Belgrade, Despot Stefan Boulevard 142, 11060 Belgrade, Serbia

Additional index words. pollen germination and tube growth, pollen nuclear status, pollen viability, sucrose, Tanacetum vulgare

\begin{abstract}
The pollen morphology of aromatic Tanacetum vulgare L. (Asteraceae), which has wide horticultural and medicinal uses, was examined using light microscopy and scanning electron microscopy. The investigation revealed that pollen grains are radially symmetrical, isopolar, spheroidal, tricolporate, and echinate-perforate. Average pollen length was $21.32 \pm 1.12 \mu \mathrm{m}$, whereas average pollen width was $20.04 \pm 0.98 \mu \mathrm{m}$ (length:width ratio 0.94). Spine length was $2.72 \pm 0.29 \mu \mathrm{m}$. Average distance from the spines was $7.15 \pm 0.31 \mu \mathrm{m}$. Pollen exine consisted of 1-3 pores. Pori are elongated and also with a distinct margin. The porus latitude is smaller than the colpus latitude. One to three perforations were noticed on $1 \boldsymbol{\mu m}^{2}$ of exine. Fluorescein diacetate was used to assess the viability of $T$. vulgare pollen. The effect of sucrose $(1 \%, 5 \%, 10 \%, 20 \%$, and $30 \%$, w/v) on pollen germination and tube growth was evaluated. Overall, the inclusion of sucrose in the medium improved both pollen germination and tube growth. Also, pollen nucleus status was determined. Binucleate and trinucleate mature pollens were observed. Overall, the palynological features of this species may be helpful for further taxonomical and pharmaceutical investigations.
\end{abstract}

Tanacetum vulgare L. (Asteraceae, common name Tansy) is native to temperate Europe, Asia, and North Africa. It has many horticultural and pharmacological qualities. Tansy can be cultivated, and it also grows spontaneously. It has been introduced to other parts of the world and in some areas has become invasive. Also, Tansy is used in companion planting and for biological pest control and sustainable agriculture. It is planted alongside potatoes to repel the Colorado potato beetle with one study finding that Tansy reduced beetle populations by $60 \%$ to $100 \%$ (Schearer, 1984). The oil of T. vulgare when rubbed on skin has been reported to repel insects (Grieve, 1971). In moderate doses, the plant and its essential oil are stomachic and cordial and they are used as a food additive (Grieve, 1971). Mikulášová and Vaverková (2009) have reported that essential oils from Tansy possess antibacterial and antiyeast activity.

$T$. vulgare is principally used in traditional Asian and North African medicine as an antihelminthic, carminative, antispasmodic, stimulant to abdominal viscera, tonic, emmenagogue, antidiabetic, diuretic and is antihypertensive (Stevović et al., 2009).

The family Asteraceae is a typical example of a eupalynous group and most of its

\footnotetext{
Received for publication 14 Dec. 2011. Accepted for publication $20 \mathrm{Jan} .2012$.

This work is supported by the Ministry of Education and Science of the Republic of Serbia (grant No. 173015).

${ }^{1}$ To whom reprint requests should be addressed; e-mail calic@ibiss.bg.ac.rs.
}

genera possess trizonocolporate pollen (Sachdeva and Malik, 1986). The pollen grains of Asteraceae have been characterized as basically helianthoid, spherical or slightly flattened, tricolporate, and echinate (Skvarla et al., 1977; Wodehouse, 1935). In vitro pollen germination and pollen tube growth are greatly influenced by different factors. For example, addition of sucrose to the germination medium improved in vitro pollen germination frequency and tube growth by preventing tube bursting (Alcaraz et al., 2011; Geetha et al., 2004). Pollen of flowering plants is either binucleate or trinucleate. Compared with binucleate pollens, trinucleate pollens are known to have a rapid germination rate but short viability (Brewbaker, 1967).

The generative nucleus of binucleate pollen divides in the pollen tube after germination to form two sperm nuclei, whereas that of trinucleate pollen divide in the anther before pollen is shed (Sugiura et al., 1998). Among the 2000 species surveyed by Brewbaker (1967), 70\% were found to be binucleate and the remainder trinucleate. Also, among the 265 families, 179 had binucleate genera, 54 had trinucleate genera, and 32 had both types of genera (Brewbaker, 1967). Pollen development and morphology are often used by paleobotanists and taxonomists to clarify the identity and classification of plant species (Mert, 2009). Ultrastructural observations under scanning electron microscopy help define pollen characteristics such as shape, size, and presence or absence of exines.

Because there are no reports on the pollen morphology of $T$. vulgare, the present report gives an account of the palynological characters of this species.
Currently, there are no published reports available on Tansy pollen viability.

Knowledge about in vitro germination, tube growth, and nucleus status of $T$. vulgare pollen is important for understanding the basic characteristics of Tansy pollen and beyond. Therefore, the objectives of the current study were to 1) determine the shape and dimensions; 2) surface morphology and ornamentation; 3 ) evaluate pollen germination and tube growth of Tansy; 4) assess viability of Tansy pollen; and 5) study pollen nucleus status.

\section{Materials and Methods}

Plant materials. The study was conducted on the wild type of T. vulgare L. 1573 in Belgrade, Serbia. The samples have been dried and prepared as herbarium specimens to deposit at the Herbarium of the Department of Biology and Ecology-BUNS Herbarium, Faculty of Natural Sciences, University of Novi Sad, voucher No. 2-2069.

Pollen viability test. A rapid method with fluorescein diacetate (FDA) (Heslop-Harison and Heslop-Harison, 1970) was used to determine pollen viability after $1-2 \mathrm{~h}$. FDA $\left(2 \mathrm{mg} \cdot \mathrm{L}^{-1}\right)$ dissolved in acetone was diluted by (1:1) $0.5 \mathrm{M}$ sucrose solution.

Anthers were longitudinally rejected and free pollen grains were stained with one to two drops of FDA.

Pollen nucleus status. The number of pollen nuclei was determined by 4', 6-diamidino2-phenylindole (DAPI) (Coleman and Goff, 1985). The content of anthers was removed by squeezing and was stained with 1-2 drops of DAPI $\left(1 \mu \mathrm{g} \cdot \mathrm{mL}^{-1}\right)$ solution prepared in distilled water. FDA and DAPI-treated microspores were examined under the Carl Zeiss Axiovert fluorescent microscope (Microlmaging $\mathrm{GmbH}$, Göttingen, Germany) equipped with a camera.

Scanning electron microscopy. The pollen samples were collected from fresh flowers and processed for scanning microscopy without the usual fixation and dehydration procedures. In the scanning electron microscopy (SEM) studies, the pollen grains taken from the anther were placed directly on the stubs and were covered with a thin layer of gold (ion sputtering coating) in a BALETECSCD 005 Sputtering Device, imaging at $15 \mathrm{kV}$, using a JSM-6390 LV (JEOL, Tokyo, Japan) scanning electron microscope. The detailed surface ornamentation and the aperture characteristics were examined under the SEM, and the microphotographs were taken.

In vitro pollen germination and tube growth. A basic medium contained $1.5 \%$ agar, different sucrose concentrations, and 3\% boric acid $\left(\mathrm{H}_{3} \mathrm{BO}_{3}\right)$. The effect of sucrose concentrations $(1 \%, 5 \%, 10 \%, 20 \%$, and $30 \%, \mathrm{w} / \mathrm{v})$ on pollen germination and tube growth was evaluated in Tansy. Pollen germination was recorded after 15 and $24 \mathrm{~h}$ on sucrose media, whereas pollen tube growth was measured after $15,18,21$, and $24 \mathrm{~h}$. A pollen grain was considered to have germinated when pollen tube length equaled or exceeded the grain diameter. To measure pollen tube growth, samples were prepared as described previously. The slides 
were observed under the Zeiss Axiovert light microscope equipped with a camera.

Statistical analysis. The measurements of the diameter, viability, and nuclei status were taken on 600 pollen grains. The means were separated using Fisher's least significant difference post hoc test for $P \leq 0.05$.

\section{Results and Discussion}

Pollen viability test. The pollen viability test was determined for 600 pollen grains of Tansy (Fig. 1A) by FDA. Pollen viability was high $(87 \%)$ after a 1 - to 2 -h staining procedure.

Pollen nucleus status. The number of pollen nuclei was determined with DAPI. An observation of 600 pollens found $88 \%$ of the pollens to be binucleate and the rest trinucleate (Fig. 1B).

Scanning electron microscopy. Scanning electron micrographic images of pollen grains were taken on 600 pollen grains of Tansy at $150 \times, 900 \times$, and $2500 \times($ Fig. $2 \mathrm{~A}-\mathrm{C}$ ). The pollen grains of Tansy are radially symmetrical, isopolar, tricolporate, and spheroidal. Exine architecture of mature pollen grains taken at 15,000× shown in Figure 2D. Ornamentation of exine is echinate-perforate. Pollen grains have characteristic spines with varying length. Spines are concave and their bases are broad. Average pollen length was $21.32 \pm$ $1.12 \mu \mathrm{m}$, whereas average pollen width was $20.04 \pm 0.98 \mu \mathrm{m}$ (length:width ratio 0.94). Spine length was $2.72 \pm 0.29 \mu \mathrm{m}$. Average distance from the spines was $7.15 \pm 0.31 \mu \mathrm{m}$ (Fig. 2C). Pollen exine consisted of 1-3 pores. Pori are elongated and also with a distinct margin. The porus latitude is smaller than the colpus latitude. One to three perforations were noticed on $1 \mu \mathrm{m}^{2}$ of exine.

In vitro pollen germination and tube growth. The length of pollen tubes on sucrose media was measured after $15,18,21$, and $24 \mathrm{~h}$ under a light microscope. The effect of sucrose on pollen germination and tube growth varied according to concentration and time. The highest germination percentage $(87 \%)$ was obtained in a medium with $30 \%$ sucrose after $24 \mathrm{~h}$ (Fig. 3C). The germination percentage steadily improved with increasing sucrose concentration, reaching up to 8.7 times higher increase for the $30 \%$ sucrose compared with the control (Fig. 4A). Also, some pollen grains were spontaneously germinated and detected under SEM (Fig. 3A-B). Pollen tube growth linearly increased with increasing sucrose concentration. The highest pollen tube length $(200 \mu \mathrm{m})$ was obtained in medium containing $30 \%$ sucrose after $24 \mathrm{~h}$ (Fig. 4B).

$T$. vulgare as well as the most of the species in Asteraceae has zonocolporate pollen (Sachdeva and Malik, 1986). A pollen spine is characteristic and significant in evolution and generic levels in the classification of this family (Zafar et al., 2007). Pinar and Dönmez (2000) reported that spine cavities of pollen exine can be used as diagnostic characters in the genera of Asteraceae. In addition, the pollen morphology of different Asteraceae taxa studied by several researchers has reported that the exine features have an importance for taxonomy and
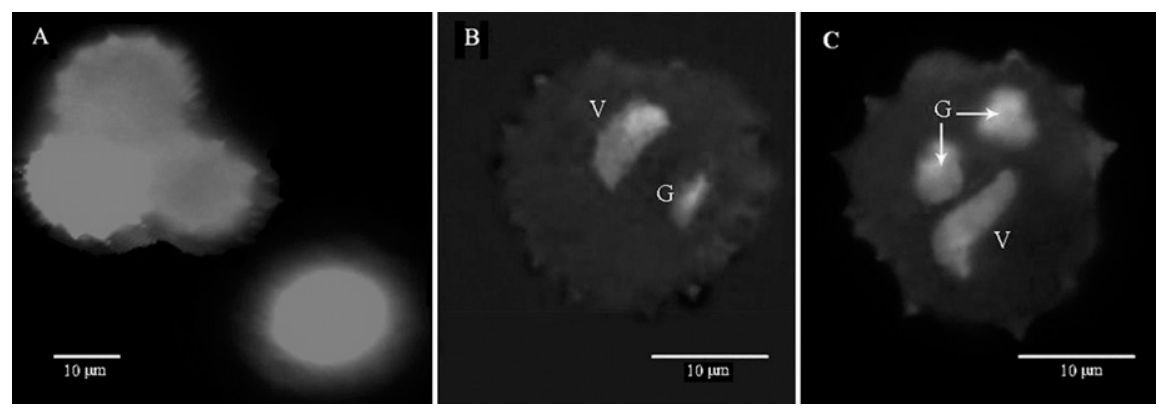

Fig. 1. (A) Fluorescein diacetate (FDA)-treated pollen grains. (B) A representative binucleate pollen with a vegetative $(\mathrm{V})$ and generative $(\mathrm{G})$ nucleus. (C) Trinucleate pollen with one vegetative and two generative nuclei.
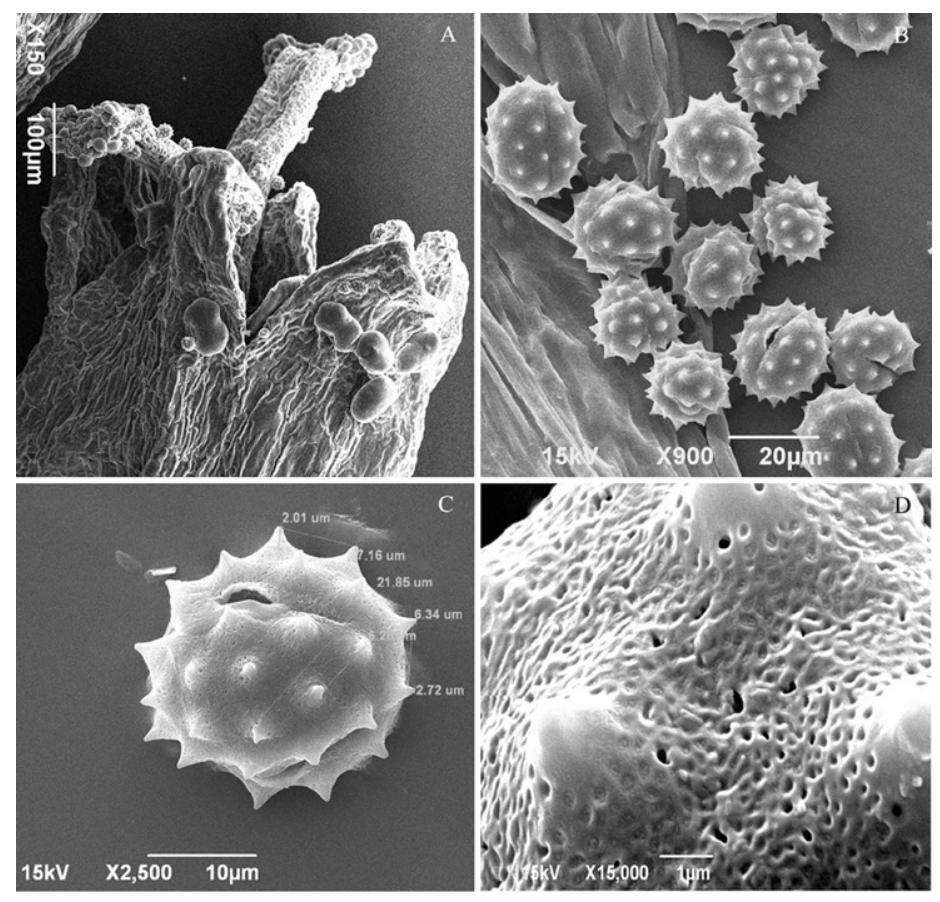

Fig. 2. (A) Scanning electron micrography of flower with pollen grains. Mature pollen grains (B-C). Architecture and ornamentation of exine (D).
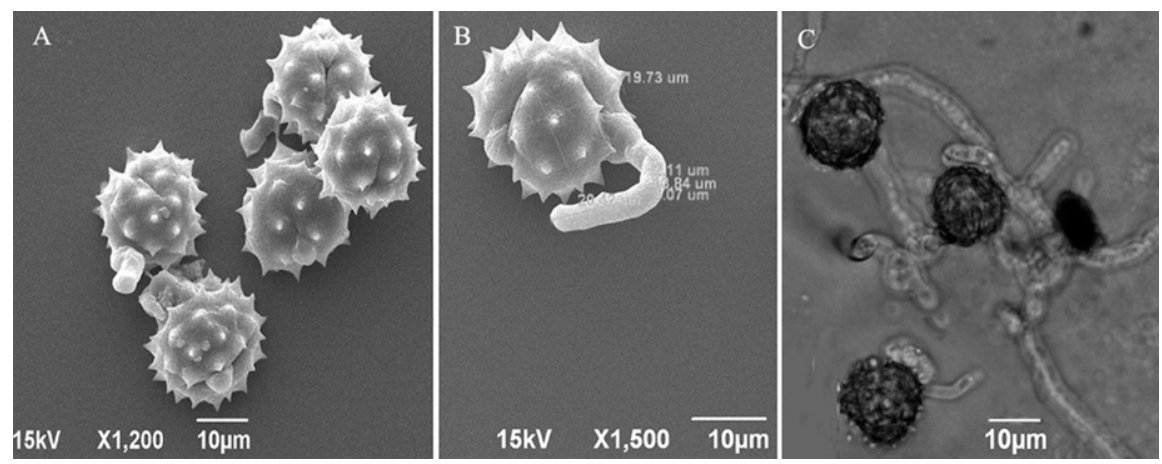

Fig. 3. (A-B) Scanning micrography of germinated pollen. (C) Germinated pollen grains on medium with $30 \%$ sucrose under a light microscope.

phylogenetic classification (Mbagwu and Edeoga, 2006; Skvarla et al., 1977). Therefore, ornamentation and spine characteristics of $T$. vulgare have been examined in our research.

The pollen grains of $T$. vulgare are radially symmetrical, isopolar, tricolporate, and spheroidal as previously examined in species of this genus (T. corymbosum subsp. orymbosum, T. armenum, T. nitens, and T. haussknechtii) (Ozmen et al., 2009). Exine ornamentation of pollen grains belonging to each taxa is echinate-perforate. The spine length of $T$. vulgare 

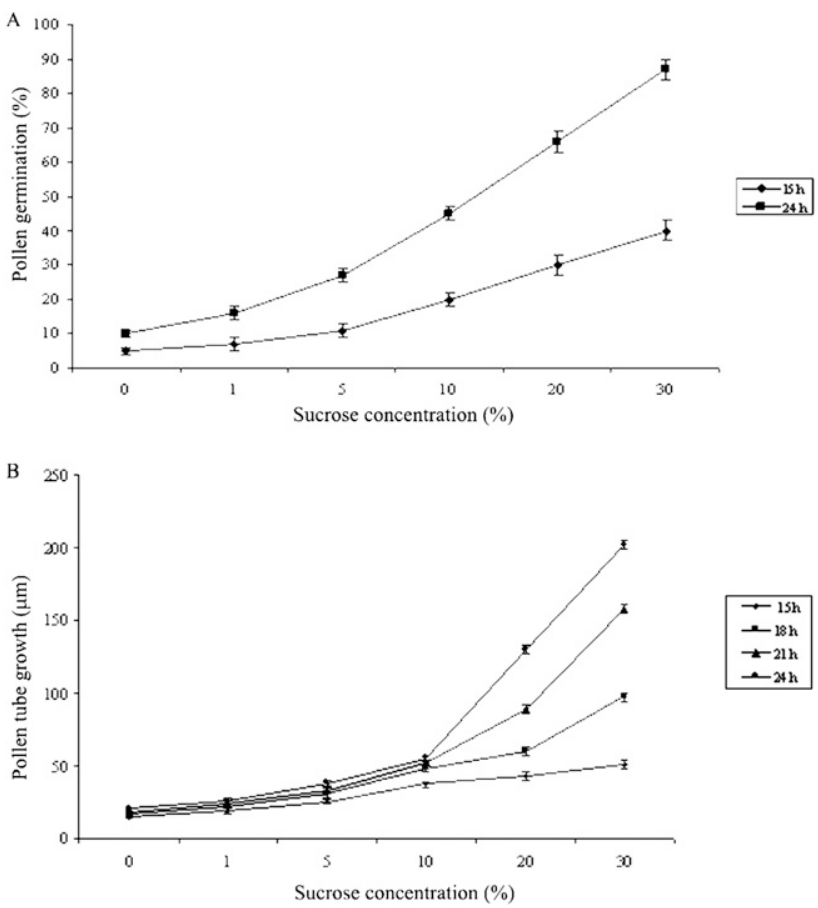

Fig. 4. (A) Pollen germination after 15 and 24 h. (B) Tube growth of Tansy on different concentrations of sucrose after 15, 18, 21, and $24 \mathrm{~h}$. Errors bars indicate \pm SD.

pollen is $2.72 \mu \mathrm{m}$, whereas spine length of $T$. corymbosum subsp. orymbosum, T. armenum, T. nitens, and T. haussknechtii is $2.62-3.38 \mu \mathrm{m}$. The spines of $T$. vulgare are longer than those many other taxa of Asteraceae (Díez et al., 1999). The equatorial axis and the polar axis and diameter of the pollen grains of $T$. vulgare are similar with four previously examined Tanacetum species (Ozmen et al., 2009).

In general, the inclusion of sucrose in the medium improved both pollen germination and tube growth for examined species and varied according to sucrose concentration. Geetha et al. (2004) reported that sucrose functioned as an osmoticum rather than an energy source for in vitro pollen germination. The beneficial effect of boric acid on pollen germination was found by Geetha et al. (2004).

Most of the pollen grains from the examined species were found to be binucleate, but some of them were trinucleate (Fig. 1B-C). The presence of both binucleate and trinucleate pollens in the same genus has been documented by some authors (Brewbaker, 1967; Lora et al., 2009). The high germination percentage of Tansy (Fig. 4A) suggests that a high percentage of the grains of this cultivar is viable. Our results showed that trinucleate pollens germinate and elongate at a faster rate but have shorter viability than binucleate pollens. This faster germination rate of trinucleate pollen, which appears to rely on exogenous sources from the start of germination, can be valuable in conditions in which rapid reproductive processes are needed (Lora et al., 2009). Trinucleate pollen is best suited for the mode of pollen dispersal that includes wind and water dispersal of pollen grains and slight increases in temperature, which accelerates female development and the whole reproductive process (Sanzol and Herrero, 2001). On the other hand, binucleate pollen, which germinate at a slower rate but survive longer, could still be available to be transferred later by pollinating insects to flowers in the female stage (Gottsberger, 1989). In the end, the presence of both binucleate and trinucleate pollens at anthesis could be viewed as a bet-hedging strategy to obtain a higher chance of fertilization (Lora et al., 2009). Pollen morphology and ultrastructure have been shown to be correlated with growth habit and pollination biology (Osborn et al., 2001). Scanning electron micrographic images of Tansy pollen grains (Fig. $2 \mathrm{~A}-\mathrm{D})$ showed that these pollen grains had well-defined exine with specific spine architecture and ornamentation. The role of the exine is to protect the male spore and gametophyte from desiccation and other dangers of subaerial dispersal. Our results are in agreement with the results that pollen grains of terrestrial taxa have well-defined exine, those of amphibious taxa have thinner exine, and the obligately submersed taxa have no exine (Cooper et al., 2000; Osborn and Philbrick, 1994).

\section{Literature Cited}

Alcaraz, M.L., M. Montserrat, and J.I. Hormaza 2011. In vitro pollen germination in avocado (Persea americana Mill.): Optimization of the method and effect of temperature. Sci. Hort. 130:152-156.

Brewbaker, J.L. 1967. Distribution and phylogenetic significance of binucleate and trinucleate pollen grains in angiosperms. Amer. J. Bot. 54: 1069-1083.

Coleman, A.W. and L.J. Goff. 1985. Applications of fluorochromes to pollen biology. Mithramycin and 4',6-diamidino-2-phenylindole (DAPI) as vital stains and for quantitation of nuclear DNA. Stain Technol. 60:145-154.

Cooper, R.L., J.M. Osborn, and C.T. Philbrick. 2000. Comparative pollen morphology and ultrastructure of the Callitrichadaceae. Amer. J. Bot. 87:161-175.

Díez, M.J., J.A. Mejías, and E. Moreno-Socías. 1999. Pollen morphology of Sonchus and related genera, and a general discussion. Plant Syst. Evol. 214:91-102.

Geetha, K., S. Vijayabaskaran, and N. Jayaraman. 2004. In vitro studies on pollen germination and pollen tube growth in maize. Food Agr. Env. 2:205-207.

Gottsberger, G. 1989. Comments on flower evolution and beetle pollination in the genera Annona and Rollina (Annonaceae). Plant Syst. Evol. 167:89-94.

Grieve, M.A. 1971. Modern herbal, The medicinal, culinary, cosmetic and economic properties, cultivation and folk-lore of herbs, grasses, fungi, shrubs and trees, with all their modern scientific uses. Dover, New York, NY.

Heslop-Harison, J. and Y. Heslop-Harison. 1970. Evaluation of pollen viability by enzymatically induced fluorescence: Intracellular hydrolysis of fluorescein diacetate. Stain Technol. 45:115-120.

Lora, J., M. Herrero, and J.I. Hormaza. 2009. The coexistence of bicellular and tricellular pollen in Annona cherimola (Annonaceae): Implications for pollen evolution. Amer. J. Bot. 96:802-808.

Mbagwu, F.N. and H.O. Edeoga. 2006. Palynological studies on some Nigerian species of Vigna Savi. J. Biosci. 6:1122-1125.

Mert, C. 2009. Pollen morphology and anatomy of Cornelian cherry (Cornus mas L.) cultivars. HortScience 44:519-522.

Mikulášová, M., and Š. Vaverková. 2009. Antimicrobial effects of essential oils from Tanacetum vulgare and Salvia officinalis L., growing in Slovakia. Nova Biotechnol. 9:161-166.

Osborn, J.M., G. El-Ghazaly, and R.L. Cooper. 2001. Development of the exineless pollen wall in Callitriche truncate (Callitrichaceae) and the evolution of underwater pollination. Plant Syst. Evol. 228:81-87.

Osborn, J.M. and C.T. Philbrick. 1994. Comparative pollen structure and pollination biology in the Callitrichaceae. Acta Bot. Gallica 141:257-266.

Ozmen, E., I. Kizilpinar, B. Ozudogru, C. Dogan, and S. Erik. 2009. Pollen morphology of some taxa of aromatic genus Tanacetum L. (Asteraceae). J. Pharm. Sci. 34:1-11.

Pinar, N.M. and E.O. Dönmez. 2000. Pollen morphology of some Turkish endemic Helichrysum gaertner species (Compositae). Pak. J. Bot. 32:295-301.

Sachdeva, S.K. and C.P. Malik. 1986. Experimental plant taxonomy. Kalyani Publications, New Delhi, India.

Sanzol, J. and M. Herrero. 2001. The 'effective pollination period' in fruit trees. Sci. Hort. 90:1-17.

Schearer, W.R. 1984. Components of oil of tansy (Tanacetum vulgare) that repel Colorado potato beetle (Leptinotarsa decemlineata). J. Nat. Prod. 47:964-969.

Skvarla, J.J., B.L. Turner, V.C. Patel, and A.S. Tomb. 1977. Pollen morphology in the Compositae and in morphologically related families, p. 141-248. In: Heywood, V.H., J.B., Harborne, and B.L. Turner (eds.). The biology and chemistry of the Compositae. Academic Press, London, UK.

Stevović, S., M.V. Surčinski, and D.D. Calić. 2009. Environmental adaptability of tansy (Tanacetum vulgare L.). Afr. J. Biotechnol. 8:6290-6294.

Sugiura, A., R. Tao, T. Ohkuma, and M. Tamura. 1998. Pollen nuclear number in four Diospyros species. HortScience 33:149-150.

Wodehouse, R.P. 1935. Pollen grains. McGraw Hill, New York, NY.

Zafar, M., Ahmad, M., and M.A. Khan. 2007. Palynology of family Asteraceae from flora of Rawalpindi-Pakistan. I.J.A.B. 9:156-161. 